authorities embark on the campaign of planned elimination of food deficiency diseases.

I wish to thank the Director-General, Army Medical Services for his permission to publish this paper.

\title{
REFERENCES
}

1. Wilson, R. P.-Rep. Giza. Ophthal. Lab., 1st-11th Reports, Cairo (19271937).

2. Feigenbaú, A.- - Ophthalmic conditions in Tropical and Subtropical Regions." Modern Trends in Ophthalmology by Frederick Ridley and Arnold Sorsby.

3. DE Silvi, K. J. L.- "The Problem of Trachoma in Ceylon." The Journal of the Ceylon Branch of the B.M.A 1942.

\section{OPHTHALMIC WORK IN A BRITISH GENERAL HOSPITAL IN NORTH AFRICA*}

\author{
BY \\ A. J. CAMERoN, Major, R.A.M.C. \\ SPECIALIST OPHTHALMOLOGIST
}

BEFORE going on to talk about eye cases as such, I should like to say something about the set-up' and layout of a Military General Hospital, as that was the' type of unit to which I was attached.

First of all, what is meant by the term General Hospital? In this country there are few, if any, functioning as such. Most of the hospitals are what is known as "Static," that is they are fixed in a given place, and do not as a rule move with any alteration in troop dispositions. The General Hospital, on the other hand, can if the situation demands it, pack up and move on. In other words it is mobilethat is the essential difference.

If the venue of your activities is to be in the country, in a foreign country, in a tropical or sub-tropical country, in a none-too-friendly country, then you are going to do more than simply set up a hospital, you are going to set up a distinct and up to a point, a self-supporting community, largely dependent upon itself for the maintenance of its own health and well-being, and exactly in so far as that is carried out efficiently, is your success as a medical centre going to depend. It is not much use having a first-class hospital if the staff are going to go down with

- malaria because of an inefficient anti-mosquito campaign, or with typhoid because the water has been ineffectively treated or with dysentery because your sanitary arrangements have been faulty.

I would stress that all this work has to be undertaken by the unit itself, that is by the medical staff and orderlies, and that, in addition, the whole setting up of the hospital is done by the unit; the putting up of hospital marquees, of theatre tents, special departments, laboratory, store tents, living tents, ablutions, etc. etc. and all the heaving and hauling connected with it, everything up to the stage where each hospital marquee becomes a fully-equipped ward.

You carry your own generator for power and light, your own $\mathrm{X}$-Ray equipment, your own special department equipment, and each person is responsible for thè setting up and the efficient functioning of his own department.

In the event of snags and difficulties, you must just make the best of it as there are no expert technicians.upon whom you can call.

* Read at a meeting of the Clinical Society of the Royal Eye Hospital, on November 24, 1944. . tReceived for publication, September 6, 1944. 
I would, however, say, that a successful liaison with the Sappers can be a very good and helpful thing.

When you are posted to a General Hospital in process of formation, you are, in this country, told to arrive at a given place at a given time. In my own case $I$ did so, and found that some 32 other medical officers had also arrived, and although quite unknown to each other, we were the staff of the so and so General Hospital, which at that stage existed only on paper.

So that altogether the conditions are a little different from being appointed to a static hospital, where you walk into a nice building and find everything laid on.

As regards ocular conditions themselves in my own cases and in my own notes they are divided into two main groups.

- 1. Battle casualties, in which I include injuries as well as those caused by enemy action as the wounds are of a similar type.

2. Sick. )

To deal with Battle casualities first, they are sub-divided into two main groups (a) severe and (b) slight. It is surprising how few there are between the two, and yet that is quite understandable considering the type of missile causing the injury.

Into the severe group I place :

(a) Penetrating wounds of the eye with or without prolapse of iris or other uveal tissue.

(b) Lacerations of the globe, and deep conjunctival and scleral tears, varying in séverity, up to complete disorganisation of the globe.

(c) Lacerations of the lids with loss. of essential tissue and complicated as. such cases usually are, by deep penetrating wounds in the circumorbital region, frequently between the inner canthus and the nose.

(d) Burns.

(e) Deep penetrating corneal foreign bodies,' usually multiple.

(f) Intra-ocular foreign bodies.

(g) Cases of severe visual depression; where at a glance there is not enough seen externally to account for the visual loss.

It should be remembered that this grouping is entirely arbitrary. and that oftener than not there is a lot of overlapping. A case of prolapsus iridis, or of ruptured globe more frequently than not has also lacerated lids and deep.neighbouring wounds with or without retained foreign bodies.

Into the second group of slight injuries are placed such cases as :

(a) Corneal abrasions.

(b) Superficial foreign bodies, corneal and conjunctival.

(c) Slight cuts of the lids and surrounding tissues.

(d) Sub-conjunctival haemorrhages and cases where there is a good view of the fundus, revealing no pathology, and the visual acuity is good. 


\section{Examination and treatment of severe cases}

The procedure that I myself adopted was roughly as follows :-

As soon as possible after the soldier was settled in bed he was seen. Usually you found him with both eyes covered, and before and while you are slowly removing his bandages, it is. a great help to have a little talk with him, not only about his wounds but about himself and his affairs. The time is usually well spent in so doing, as somehow you get off on the right foot, and the lad feels that someone has an interest in himself as well as in his wound, and that means a good deal. Having removed the bandages, have a careful look over the whole field before touching anything, noting the condition of the lids, the apposition of lacerated edges, any loss of tissue, or inversion of torn tissue, and noticing the position of any neighbouring wounds particularly in the region of the inner canthus, or between the canthus and the nose. Next, the whole field is carefully cleaned with pledgets of cotton wool out of saline. A canthal wound, if present, is carefully cleaned out, using if necessary a pair of fine forceps, all possible extraneous matter is removed, and buried or distorted pieces of lid skin and lash margin are freed, and if there is the faintest chance of them being viable they are retained and replaced as well as possible.

A blunt-pointed probe about as large as a large lacrimal probe is very gently made to feel its way about any open wound to find any possible superficial foreign bodies. ' Only when all this is done does one turn one's attention to the eye itself. The lids are carefully separated and the state of affairs found simply by looking. There is very little justification, as far as the globe is concerned, for handling, probing or pressing. A disorganised globe can be seen at a glance, indeed the diagnosis has frequently been made before the lids are open, as 'scleral and uveal tissue has been seen extruded on to the lower lid. A prolapse of iris is usually easily seen when one has had experience of that sort of thing, even if there is present a full hyphaema. The same applies to lacerations of the cornea and cornea-sclera.

Rather more difficult, and frequently very difficult, are the small perforations with (?) retained intra-ocular foreign bodies, where the perforation has sealed and the tension is normal. Having examined the case in this way, and looked for the presence of a fundus reflex and made if possible an ophthalmoscopic examination, an immediate decision is come to as to whether or not the case requires to go to the theatre, for, for example, abscission of prolapse and conjunctival flap, or for repair of globe laceration, or for the magnet, or for a frill enucleation in cases of torn and disorganised globes. 
As soon as this decision is come to the portable X-Ray plant is sent for to examine the whole area for retained metallic foreign bodies.

Examination or inquiry regarding other injuries is madé, and if necessary the Surgical Specialist is asked to see the case so that, if any other operative procedure be deemed essential from his view point, it can be done by mutual arrangement at the same time and under the same anaesthetic.

The entire "findings are carefully written up on the patient's cards, and you are ready to proceed to the next case.

Whether or not a case of an intact eye but grossly torn lids is immediately operated upon, depends on, first the patient's general condition; secondly, the presence or absence of foreign bodies in surrounding wounds, and thirdly, the state of congestion in the theatres.

Careful replacement and apposition of tissues as soon as possible is in my opinion a desirable thing. Many of these cases are seen with advantage in conjunction with the ear, nose and throat surgeon. So much for gross bulbar injuries.

Deeply imbedded foreign bodies in the cornea which have been driven well into the substantia propria almost up to the endothelium are best left alone and it is my opinion that their future behaviour cannot with any certainty be foretold. I have, over a considerable period, watched such a case with the slit-lamp, and while one or two particles in time found their way to the surface and could be picked out easily, others which appeared of a precisely similar nature remained quite unmoved. Unless they are very numerous, interference with vision is less than one might expect.

In cases where the foreign body, while being firmly held in the cornea, perforates Descemet's membrane and is protruding into the anterior chamber, the condition is different. Such foreign bodies are usually larger that the previous one referred to. I have had two such cases, where pieces of spectacle lens were driven through the cornea and protruded into the anterior chamber. The finest iris forceps could not touch them through the corneal wound of entrance, and indeed this is a dangerous procedure, as you are likely to push the foreign body right into the anterior chamber. In the cases referred to above, I passed a sharp double-edged broad needle into the anterior chamber from the limbus, got the point of it between the lens capsule and the glass and by gently raising the point was able to push the foreign body: so far into the cornea that I was able to grip it with a fine toothed forceps from the epithelial surface and remove it, with no subsequent loss of vision. The successful accomplishment of such a manoeuvre twice in succession is more a matter of good luck than good guidance. 


\section{Burns}

These are mostly severe, and involve the whole face, neck and hands: They are caused frequently in the Royal Armoured Corps by a tank being hit and taking fire inside. They are also very frequent in R.A.F. crashes.

The procedure in 'such cases was to clean the eye and all the skin as carefully as possible with warm water or saline, instill atropine and a bland ointment between the lids. If necessary the whole area of the face and neck is covered with Tulle Gras or vaseline mesh gauze and dusted with sulphonamide powder, the whole covered by a lint face mask.

I have often wondered what is the ultimate end of cases of burns of the eye that show completely lifeless and ischaemic segments of the conjunctiva and sclera. The hands were cleaned and treated, sometimes with continuous saline drip in a large waterproof bag made like a glove, or alternatively with vaseline gauze and sulphonamide.

\section{Intra-ocular foreign bodies}

This is a subject of paramount importance. My own opinion is that they are not so numerous as is generally thought. In my own hands their successful treatment, that is their extraction with recovery of vision has been disappointing rather than otherwise, but in extenuation $I$ think there are many reasons why this should be so.

First of all, a large percentage is non-magnetic and I think that percentage tends to increase. Even if you remove another foreign body from the skin quite near the eye and find it magnetic, that is no criterion that the intra-ocular one is. I have had cases where an intra-ocular foreign body has been found by X-Ray, "carefully localised and magnet extraction attempted with no response. The case is at once $\mathrm{X}$-Rayed again under exactly similar conditions and it is found that there has been no shift, yet in at least two such cases when the foreign body was ultimately removed from the enucleated eye, cleaned, and again tried with the magnet it was definitely magnetic. The great difficulty, in my opinion, is localisation. I personally have not had any cases where I could actually see the foreign body. There has always been either a marked localised or generalised haemorrhage and reaction, and its attempted removal has been a question of accurate roentgenological localisation. Given that, then with either the giant or the hand magnet, a direct approach may be made, and if the localisation is good, I think it is even justifiable to insert the point of the hand magnet into the vitreous through an incision in an attempt to get a successful removal. 
Localisation in the field, however, is excessively difficult. Sweet's apparatus is cumbersome and is anyhow not in supply, although one American hospital which I knew did have the apparatus in Tunisia. The MacGregor frame depends on the stereoscopic principle with its drawbacks. For this reason I have for some months past, in conjunction with my colleague the radiologist, been endeavouring to devise a rapid and reliable method of localisation by the injection of opaque dyes.

So far the work has been carried out on rabbits and seems to promise quite well.

No case should be given up until several attempts with the magnet have been carried out.

It will be interesting ultimately to read of the end and late - results of magnet removal.

\section{Missiles-Their relative frequency and behaviour}

In trying to assess the relationships between the type of missile and the numbers of wounds caused by it I find that in my own cases the largest numbers of injuries were caused by the following types of missile in order of frequency :-

1. Mortar fragments-this pre-eminently headed the list.

2. "S," Teller, and other anti-personnel mines.

3. Shell splinters, bomb splinters and extraneous material, such as earth, wood and stone.

4. Rifle, machine-gun and Tommy-gun bullets "303."

The most severely injured cases I have seen, and I think all the cases of bi-lateral blindness' I have seen, were caused by exploding mines and booby traps, the most severe case of all, being a young soldier of 19 who had both eyes blown out, his nose split, his face lacerated and both hands blown off above the wrist, as well as abdominal and lower limb injuries.

The behaviour of foreign bodies can seldom in any sure way be foretold, nor can the route they are likely to have taken be in any way deduced from a study of the wound of entry. I am referring chiefly to retained foreign bodies and 303 bullets. I think everyone must have seen the most inexplicable happenings and lack of happenings. I can think of a case where a rifle bullet entered the inferior surface of the ramus of the mandible of the right side, fractured it, passed out through the alveolar margin into the maxilla, into the antrum, fracturing the outer wall, out of the antrum above, missing the globe of the eye entirely, and ending up by burying itself in the frontal sinus of the same side, with no reason as far as I could see, why or how the eye was actually avoided.

In another case, a 303 bullet passed in at the right canthus with 
sufficient velocity to make only a tiny wound of entry. X-Ray showed the bullet to be in the nose, high up on the same side. The odd point was that the X-Ray showed the bullet to be pointing outwards, instead of in, and secondly the patient's only complaint was of diminished vision in the opposite eye, which showed on examination definite traumatic change and haemorrhage in the lower part of the fundus.

Quite apart from the eye I saw a case where a bullet entered the neck in the region of the great vessels, appeared to pick its - way carefully among the fascial planes and bury itself in a cervical vertebra without doing any other discoverable injury to anything.

Quite the most remarkable case of a foreign body in this area which came under my care was one in which there was a wound in the left inner canthus, extending fairly deeply and involving the inner quarter of the upper and lower lids, including the puncta and the caruncle. The eye itself on that side was undamaged, and the patient had no complaints to speak of, although he was dripping from his nose what I took to be cerebro-spinal fluid, which led to the query of injury to the crista. Nothing was felt with the probe; and the case was at once X-Rayed. The visual acuity of the right eye, that is an the side opposite to the wound was grossly diminished and no fundus reflex was seen. This was presumed to be due to intra-ocular haemorrhage. The tension of the eye was normal. The X-Ray picture showed a foreign body of relatively colossal proportions lying on the left side involving the floor of the orbit, the greater part of the maxilla, and extending from the nose outwards to the zygoma, and extending far backwards. Its removal was attempted and presented very great difficulties, as it was firmly wedged into position, and there seemed no direction large enough to get it out, and it could not be turned in any way. The assistance of the ear, nose and throat surgeon was a great help, and although it was ultimately removed by an incision extending over the lacrimal sac region, and sweeping down and out across the maxilla, turning back a large flap, it was at one time so difficult that a modified Krönlein was for a moment contemplated. On removal it measured two and a half inches by one and a half inches by one inch. The wound healed although I don't quite know what happened inside, but when he' was sent on to the base later for further examination he was very fit. This foreign" body with the notes and X-Ray were sent home to the Imperial War Museum.

It is difficult to remember all one's cases at once as they were very numerous, but I should like to put on record one case of complete bi-lateral blindness from a gun-shot wound of the occipital region, which wound at the time when I saw it was in a state of fungus cerebri. 
Two cases of blindness due to vitreous haemorrhage which looked as though they might well go on to retinitis proliferans. In neither case was there in either eye any sign of injury, and, in each case, the history was that the man had been blown up; and it was assumed that the eye condition was the result of blast.

One case of septicaemia and cavernous sinus thrombosis (seen and diagnosed by several physicians and surgeons) was in the recovered state when I saw him except that he still had a contralateral sixth nerve palsy. The recovery was attributed to the use of penicillin (July, 1943). Severe orbital cellulitis was encountered twice only, once following a compound gunshot wound involving the outer wall of the orbit, and once following one of my own enucleations for endogenous panophthalmitis.

In all that I have said so far I would ask you to bear in mind that although we were a very large hospital having as many as 1,700 beds occupied we were relatively far forward and during the campaign in N. Africa and later during the campaigns in Sicily and Italy we functioned exclusively as a casualty clearing station. Patients came at all hours and in large numbers, sometimes as many as 400 at a time. They had to be dealt with rapidly and evacuated quickly to make room for the next lot. Treatment had therefore to be modified accordingly. Evacuation was by ambulance, train and air.

Finally the second group of cases, namely the Sick.-Those people whose ocular condition or complaint was not attributable to enemy action, battle casualty or injury.

A very striking thing is that during a campaign the numbers of ${ }^{\circ}$ sick are relatively low, and they really are sick. After a campaign and between campaigns when divisions come back to rest, the numbers immediately go up rapidly, and the nature of the cases alters considerably. In other words, while active operations are going on the soldier has a lot to think about in addition to himself. But during a resting period he can really get down to some serious introspection, and carefully overhaul himself. I do not mean that the bulk of the cases are functional, very much the reverse. The point I would make is that during active operations it is amazing with what disabilities some people are able to carry on, septic hands, multiple desert sores, etc., even under very adverse conditions of personal discomfort and privation.

The cases seen in this second group of sick are divided into:

(a) Cases with objective findings, by which I mean that something was found to be amiss with the eye or its adnexa on examination.

(b) Cases with only subjective symptoms. Taking this in its broadest sense I included all cases of refraction. [The actual number seen in each of those groups was very large indeed.] 


\section{A. J. CAMERON}

In the first division the types of cases seen in the order of frequency were: (a) Conjunctivits in all its forms. (b) Ulcerative keratitis in its most common form. (c) Blepharitis. (d) Corneal abrasions and foreign bodies. (e) Meibomian cysts and hordeola. (f) Iritis and iridocyclitis. (g) Non-purulent keratitis : Superficial punctate; Acne rosacea; Disciform ; Interstitial: (h) Trachoma. (i) Symblepharon.

The cases under $a, b, c$ and $d$ were very numerous, the others less so, and not, I think, more relatively frequent than in civil practice. I did not see one case of acute dacryocystitis, nor did I see a case of ocular myiasis.

The commonest type of conjunctivitis was rather different from what one has been accustomed to see, in that the bulbar conjunctiva was nearly always involved and showed numerous small areas of haemorrhage of the flame-shaped type, almost like a resolving sub-conjunctival haemorrhage. These were very numerous near the limbus, and numerically varied with the severity of the case. The best form of treatment ultimately decided upon was simply to paint the lids with silver nitrate, followed by a simple irrigation and ointment. Both eyes were usually done at a sitting and repeated in 48 hours if necessary. Dark glasses were given if required. Recovery, was a matter of about a week. From local Arab oculists I learned that this condition is one of their most lucrative forms of income, and that what little of their faith is not placed in Allah, is entirely invested in silver nitrate. Repeated examination showed the white staphylococcus to be the usual ơrganism present.

The corneal ulcers were frequently of the multiple marginal type and responded well to the exhibition of vitamins and dietary adjuvants.

The cases of trachoma were móstly in Italian prisoners of war, or in the local Maltese Labour Battalions, although one or two primary cases were suspected in our own troops and quite a number were reported in a personal communication from the Americans.' The treatment adopted was :

1. Segregation. 2. Sulphonamides by mouth. 3. Silver nitrate to the lids.

Copper was not mućh used. This is a common disease among the Arabs and I believe that the results of sulphonamide therapy are very satisfactory.

With the second division of the sick group, namely the subjective cases, it is a little more difficult to deal. Straightforward cases of refraction were dealt with at once and the soldiers supplied with spectacles on the spot; one, two or even three pairs as the case merited. 
While on this subject of refraction I should like to state that after examining a large number of cases over a relatively long period I formed the opinion that myopes in sub-tropical countries tend, with a definitely less strong lens, to get as good vision as they previously had, and that low myopes who required a correction to get $6 / 9$ or better, could read $6 / 6$ easily without a correction. This occurred so consistently as to impress itself upon me. I have not, I am afraid, a scientific explanation to offer. It might be partly that the bright light causes a smaller pupil or that these men had become accustomed to gazing into the wide open spaces and leading an outdoor life. One was able to check the soldier's previous correction from that document known as A.B.64 Pt. 1:

For the most part the other cases which were not refraction complained of :

1. Eye ache; 2. Eye strain; 3 . Headache; 4. Difficulty in driving at night; 5. Difficulty of reading in the evening; that is difficulty in maintaining accommodation just like a commencing presbyope, although the majority were quite young men. Each case of headache had his refraction done, his fundi examined and his field of vision checked to exclude any ophthalmological evidence of any organic cause. Very seldom was anything found to which the symptoms could be attributed. I have frequently been asked if any of these cases were functional. That is a very difficult question to answer, as there are always a few "old soldiers," no matter what their age is. On the whole, I am of the opinion, that these cases were not functional in the ordinary sense, that is to say, they were not without some little basis of cause. These men were in the open all day long, in great heat and exposed to a relentless sun, with unrelieved glare all the time. Thèy had no protection, no dark glasses, no sun helmets, not even the little protection provided by the peaked cap, their headdress being the official cap F.S. Drab or "For and Aft." They were forced to keep their eyes screwed up all day, and in going into a tent or bivouac they were quite unable to see anything during the period of adaptation, and this in many undoubtedly produced a condition of eye-consciousness. WVith the advent of the winter months there was a noticeable falling off of such cases. Nearly all were helped by a little talk and the assurance that their eyes had just been carefully examined and found healthy, and the proof that their visual acuity was good.

In a few cases for psycho-therapeutic reasons it was deemed advisable to give dark glasses for a little time.

True night blindness, retinitis pigmentosa, was found on two occasions, and in one or two cases the defective vision was due to myopic degenerative changes at the macula.

I should like to refer back and say that in cases of severe 
bilateral eye injury, unless I felt tolerably certain that a certain amount of vision was present, I did not ask-him how much he could see because of the adverse psychological effect this had in cases of complete visual loss.

\section{Discussion}

Following this paper Major OLIVER said that he proposed to alter the plan of the meeting somewhat. Major Cameron had raised several points of great interest as regards "follow-up" and he felt that it would be valuable to have a discussion instead of proceeding immediately to the next paper. Major Oliver thanked Major Cameron for his most interesting paper and said that he noticed several members who had seen foreign service present: he hoped that these members would give their comments on Major Cameron's paper and in addition any general experiences which they might care to relate would not be considered out of place. As regards the question of follow-up of severe burns and foreign bodies mentioned by Major Cameron, Major Oliver suggested that members of the E.M.S. who were present should deal with this point.

Captain G. C. PRITCHARD, R.A.M.C., said that after many months in a static unit in which he faithfully noted refractions in the soldier's pay-book he was delighted to hear from Major Cameron that notes in that document known to the Army as A.B. 64 part 1 had been found of value. Later in a forward B.L.A. Hospital he has found the main problem to be one of disposal of large numbers of cases, many trivial. The Army machine was in the main extremely efficient. A job he (Capt. Pritchard) rather enjoyed was the construction of temporary artificial eyes to replace those accidentally broken. This he did in conjunction with the Dental Surgeon. They first made a stent mould of the socket. This was then used to make a plaster impression. Finally he used acryllic resin to make a plastic prosthesis. With this makeshift the soldier could carry on comfortably for many months if necessary.

Major J. MinTon welcomed Major Cameron's emphasis on versatility. He himself had been a little worried by having to do most of his work in Baghdad in the local optician's shop. He had been impressed by the small number of Europeans in Baghdad who had developed trachoma. Like Major Cameron he had seen good results in trachoma from sulphonamides. In Ceylon. he had been interested to find much superficial punctate keratitis in natives but little in Europeans.

Dr. W. T. C. LUMLEY said that from his Horton experiences he would agree with Major Cameron that the end results of intraocular foreign bodies were disappointing. Even when removed retinitis proliferans or detachment was liable to ensue. The occasional spectacular success was sufficiently frequent to encourage active surgery. Glass injuries as had been seen following flying-bomb injuries had been most depressing.

Mr. L. H. SAViN also thanked Major Cameron for a stimulating paper. $\mathrm{He}$ himself had found the method of localisation best in which the foreign body was placed by its relationship in anterior and lateral $X$-ray pictures to a ring of known size stitched to the conjunctiva concentric to the limbus. He would qualify the general gloom regarding non-magnetic intraocular foreign bodies by saying that the results were generally good where the foreign body was in the anterior segment of the eye. He had once extracted a piece of copper from the vitreous under ophthalmoscopical guidance and using a small crocodile forceps through the scleral perforation. The patient got $6 / 18$ vision and he felt very pleased with himself, until Miss Orr-Ewing showed him the patient after 2 years with a retinal detachment The cases he liked least were the people with bilateral optic nerve iujuries. He had seen three since $D$ day. While agreeing with Major Cameron that versatility was necessary in military surgery he confessed alarm when on occasion he had to deal with wounds involving frontal lobe or even that capacious cavity the antrum, from which he had one day fished out a completely severed. upper lid, carried into the tissues by shrapnel. He wondered whether the good results quoted for suphonamides in trachoma were not due merely to clearing up the concurrent secondary infections.

Professor SoRSBY said that doubt about the efficacy of sulphonamides in trachoma nowadays savoured not of reasonable scepticism, but of purblind and almost halfwitted obstinacy. He had been able to cure all his recent Swanley cases by 
sulphonamides and local painting of lids with sodium sulphacetamide. It was a mistake to assume that just because a disease was of virus origin sulphonamides would not help it.

Major J. O. Oliver said this appeared to be the place to mention penicillin. He had seen a case of cavernous sinus thrombosis with staphylococcal meningitis recover with penicillin. There was a very definite sphere for penicillin in eye work. Major Oliver then called on Dr Rowland Hill for his paper.

Dr. T. Rowland HiLl said that as a physician he would confine his remarks to that portion of Major Cameron's paper in which he so wisely stressed the importance of general medical hygiene. After six months in a rather frowsy static hospital, the recondite wisdom of the Army Council had seen fit to transport him to tropical Nigeria. Here conditions were apt to be primitive. - On one occasion he was forced to live for seven days on a diet consisting of tinned cherries. He paid a high tribute to the negro inhabitants of Nigeria. In spite of some African "trickiness" he had found their financial and other morals the' equal of those he had known in Harley Street. At first he had been posted to a hospital for native troops, where his ignorance of the language had necessitated methods akin to those of a veterinary surgeon. Sanitary conditions were poor in that "white man's grave." At Ibadan, the greatest city of Africa, he had found a town of corrugated iron with only one lavatory to every 3,000 persons. A Welshman had been elected by the local population as its kinglet. Malaria was rife, and the only cows in town were kept behind mosquito netting. Malignant tertian malaria was everywhere with its cerebral, cardiac and intestinal complications. He saw much blackwater fever. Infantile mortality was 50 per cent. among the natives. Intravenous quinine was of ten necessary. Immunisation against yellow fever was fairly effective. Poverty was dreadful. He had not been surprised at the popularity of palm wine as a means of dulling sensibilities. This beneficent liquor was already high in alcohol content, when tapped from the parent palm trunk. Dr. Hill showed the society many pleasing examples of native carvings in some of which could be noted the omnipresent West African condition of umbilical hernia.

\title{
SOME OBSERVATIONS ON A TENDENCY TO NEAR-POINT ESOPHORIA, AND POSSIBLE CONTRIBUTORY FACTORS:
}

BY

\author{
Major D. D. Stenhouse Stewart, R.A.M.C.
}

IN spite of the interest devoted to it by competent observers during the past hundred years, there are many aspects of the physiology of vision which offer scope for further elucidation by simple experiment, mass observation, and statistical analysis.

Medical Officers in Industry and in the Services are better placed than many of their colleagues for purposes of this kind, as it is a simple matter for them to obtain a more general sample of the population to serve as " controls."

The study by Mann and Archibald (Brit. Med. Jl., 1944, Vol. I, p. 387) of a group of 28 women satisfactorily employed in extremely fine work in a factory is an excellent example of opportunities constantly available to extend the limited knowledge and

\footnotetext{
- Received for publication, August 12, 1944.
} 